\title{
Correction to: Counting Minimum Weight Arborescences
}

\author{
Koyo Hayashi ${ }^{1} \cdot$ Satoru Iwata ${ }^{1}$
}

Published online: 4 October 2018

(C) Springer Science+Business Media, LLC, part of Springer Nature 2018

\section{Correction to: Algorithmica https://doi.org/10.1007/s00453-018-0426-5}

The HTML version of this article as originally published contains an error: What is presented as Equation 4 is actually the equation that is correctly presented later in the article as Equation 6. The HTML for the article has been corrected as Equation 4 is now correctly presented.

Publisher's Note Springer Nature remains neutral with regard to jurisdictional claims in published maps and institutional affiliations.

The original article can be found online at https://doi.org/10.1007/s00453-018-0426-5.

$\varangle$ Koyo Hayashi

koyo_hayashi@mist.i.u-tokyo.ac.jp

Satoru Iwata

iwata@mist.i.u-tokyo.ac.jp

1 Department of Mathematical Informatics, University of Tokyo, Tokyo 113-8656, Japan 